\title{
Ser indio y ciudadano en el norte chileno. Etnicidad y estatus de pertenencia a la comunidad nacional y política ${ }^{1}$
}

\author{
Vivian Gavilán Vega²
}

\begin{abstract}
RESUMEN
Presento resultados de investigación sobre los procesos identitarios de la población que se adscribe étnicamente en la Región de Tarapacá, norte grande de Chile. Reflexiono sobre las formas que adquieren las etnicidades, las nacionalidades y sus vinculaciones con la ciudadanía. La distinción entre membresía étnica, membresía nacional y membresía a la comunidad política facilita la comprensión de la realidad regional. Si bien la condición de "indio" va dejando atrás su pasado colonial para transformarse en un puente hacia la inclusión social, el desarrollo de una conciencia crítica respecto de la hegemonía del Estado y nación monocultural es incipiente. Los datos obtenidos indican que la etnicidad emerge como respuesta a la oferta del Estado y va configurándose, lentamente, un proceso de demanda al mismo. No obstante, la conciencia étnica se va expandiendo. Las identidades étnicas en el actual escenario político nacional van abriendo el camino hacia una nueva forma de inclusión social.
\end{abstract}

Palabras clave: Etnicidad, nacionalidad y ciudadanía, pueblos originarios, identidades sociales.

\begin{abstract}
Based on the data obtained from research conducted between 2006 and 2009 on the identity processes of a population ethnically ascribed in the region of Tarapacá, Northern Chile. I reflect on questions of ethnicity, nationalityand their links to citizenship. The distinction between ethnic membership, national membership and membership in the political community facilitates understanding of regional realities. As the status of "Indian" is leaving behind its colonial past to become a bridge to social inclusion, the development of critical awareness of the hegemonic state and national monoculture is emerging. The data presented here indicates that ethnicity emerges as a response to the offerings of the State and configures itself, slowly, in a process that demands the same. Nevertheless, ethnic consciousness is expanding and the ethnic identities on the current national political stage are opening the way for a new form of social inclusion.
\end{abstract}

Key words: Ethnicity, nationalism and citizenship, Indigenous peoples, Social identities.

\footnotetext{
1 El presente artículo presenta resultados de investigación del proyecto Fondecyt № 1140022 Tradiciones Culturales de Género y Etnicidad en la Colectividad Aymara de la Región de Tarapacá y el Convenio de Desempeño UTA - MINEDUC HACS y FIP. Artículo
}

recibido 17 de julio de 2013, aceptado el 6 de junio de 2014 y corregido el 25 de diciembre de 2014.

2 Facultad de Ciencias Sociales y Jurídicas, Universidad de Tarapacá (Chile). E-mail: vtgavilanv@uta.cl 
El censo poblacional levantado en Chile el año 2002 identificó por primera vez ocho grupos étnicos por adscripción de los ciudadanos; el anterior (1992) reconoció solo a cinco colectividades. Un dato de la realidad que muestra rápidos cambios en la posición que ocupan los pueblos originarios en el Estado y nación chilenos. La comprensión de los procesos identitarios de la población que se adscribe étnicamente en la Región de Tarapacá, norte grande de Chile, constituye el principal propósito de este artículo. Las dinámicas sociales, culturales y étnicas constituyen su principal interés. En particular, me interesa abordar las especificidades que adquiere, en esta región, la cuestión de las etnicidades, las nacionalidades y sus vinculaciones con la ciudadanía.

La mayoría de la población que declaró pertenecer al pueblo aymara en 2002 reside en las regiones de Tarapacá y Arica-Parinacota, en el extremo norte de Chile. El 10,7\% (29.165 personas) de la población tarapaqueña dijo ser aymara. En tanto que quienes se adscriben al pueblo quechua solo alcanzó al $0,4 \%$ (1.084 personas). En esta región hallamos, también, un importante contingente de población chipaya, grupo étnico cuya comunidad principal se ubica en territorio boliviano, a pocos kilómetros de la frontera con Chile, en el salar de Coipasa. Registran una larga historia de inmigración hacia el Pacífico, pero lamentablemente no contamos con mediciones que informen sobre la cantidad de personas que residen, de manera temporal o definitiva, en el norte grande. La comunidad chipaya ha mantenido lazos estrechos durante todo el siglo XX con las comunidades aymaras, participó de la influencia del ciclo de exportación del salitre (Metraux En: Powels, 1998) y continúan distinguiéndose tanto de los aymaras de Bolivia como de las colectividades indígenas que se adscriben a la nacionalidad chilena (Cf. Wachtel, 2001; Acosta, 1997; Muñoz, 2010).

El estudio consideró a estas tres colectividades que se identifican como grupos étnicos diferenciados las que, a pesar del deterioro en el manejo de las lenguas originarias, les corresponden tres idiomas: aymara, quechua y chipaya. Tanto los datos obtenidos aquí como estudios recientes en el ámbito de la religiosidad y de las prácticas para la salud dan cuenta de una sola tradición cultural ${ }^{3}$. Esto implica que las prácticas culturales de las comunidades rurales de valles y altiplano, así como de la población que se adscribe étnicamente en las ciudades de la costa forman parte de una tradición cultural: aquella que se ha denominado "Cultura Andina" (Gavilán et al., 2011). Asimismo, se observan tres nacionalidades: chilena, boliviana y peruana. Siendo esta última la menos representativa en términos de adscripción étnica.

Para comprender estas dinámicas parto por contextualizar la cuestión indígena definiendo los conceptos claves. Continúo con los resultados obtenidos respecto de la membresía étnica para dar paso a la membresía nacional y terminar con algunas consideraciones sobre el tipo de ciudadanía que ejercen estas colectividades.

\section{La cuestión indígena. Etnicidad, nacionalidad y ciudadanía en la Región de Tarapacá}

En la actual Región de Tarapacá, norte grande chileno, se identifican dos colectividades que dicen descender de los pueblos originarios del área surandina, que en la actualidad son reconocidos por el Estado chileno: el quechua y el aymara; una reconocida por el Estado boliviano: chipaya; dos lenguas originarias: aymara y chipaya ${ }^{4}$; una tradición cultural con raíces coloniales y prehispánicas; y, tres nacionalidades a las cuales se adscriben: chilena, boliviana y peruana. Para comprender estas dinámicas se precisa distinguir, por una parte, cultura, lengua y etnia; y por la otra, nacionalidad y etnicidad. Aunque están estrechamente vinculadas, remiten a ámbitos diferentes de la diversidad existente en este territorio. La diversidad idiomática no es sinónimo de diversidad cultural. Si bien la lengua es un referente importante de la cultura ella

\footnotetext{
3 El pueblo aymara, quechua y chipaya comparte una misma tradición cultural en salud. Esto es, los marcos conceptuales serían los mismos, con variaciones de una misma matriz cultural. Lo mismo ocurre con las prácticas religiosas.

4 Es así porque quienes se adscriben al pueblo quechua no tienen manejo de la lengua.
} 
no es sinónimo de cultura. Diferentes lenguas pueden ser portadoras de tradiciones culturales similares (Díaz-Coudier, 1998). Cultura es un concepto con múltiples acepciones. Entre los aspectos críticos que destacan hoy es su deshistorizacion y cierta tendencia a su reificación. Appadurai (2001) propone que en la sociedad contemporánea es recomendable entenderla más como adjetivo que como sustantivo. Pensarla como una dimensión que pone atención en la diferencia que resulta de haberse corporizado en un lugar y una situación determinados. Si seguimos a Benhabib (2006), debemos considerar que desde una perspectiva histórica, el análisis de la cultura implica distinguir entre el punto de vista del observador social y el del agente social. Desde esta perspectiva la unidad y la coherencia de "la cultura aymara" o "la cultura chipaya", como entidad observada, es impuesta por el antropólogo y por las elites locales. Por el contrario, quienes participan de estas experimentan sus tradiciones, historias, rituales y símbolos, herramientas y condiciones materiales de vida a través de relatos narrativos compartidos, aunque también controvertidos y factibles de ser rebatidos. Por otra parte, considerar las tradiciones culturales de los descendientes de los pueblos originarios desde el punto de vista histórico implica asumir que estas son resultado de los procesos coloniales y neocoloniales regionales, por lo cual no están integrados unos a otros. Las tradiciones culturales de los pueblos originarios no son puras y las de los no indígenas en la región no son mestizas. Son "mixtas", hechas de continuidades y discontinuidades; $y$, estas últimas se ubican más en el orden temporal que en el orden espacial (Bastide en: Cuche, 2000). Las continuidades culturales afirmadas serían más componentes para producir etnicidad que diferencias culturales propiamente. Como afirma Bartolomé, "las categorías étnicas actuales pueden ser entendidas como construcciones ideológicas resultantes de las respectivas historias de articulación interétnica de cada grupo" (1997: 47).

La etnicidad como dimensión de análisis de las relaciones sociales puede ser realizado en base a cuatro aspectos (Poutignat y StreiffFenart, 1995): la atribución categorial, las fronteras del grupo que sirven de base a la dicotomización, la fijación de los símbolos identitarios que fundan la creencia en un ori- gen común y el relevamiento de la dimensión étnica de la identidad social en los procesos de interacción social. Esto porque los grupos sociales etnizados forman parte de contextos sociopolíticos y socioeconómicos mayores. Los pueblos indígenas son colectividades subordinadas, por lo cual el carácter étnico de los mismos es una respuesta cultural a los retos interpuestos por el colonialismo, en el cual colonizadores y colonizados se enfrentan como grupos dominantes y subordinados. En este sentido, los procesos identitarios como las relaciones interétnicas dependen en gran medida del contexto estructural en el que ocurren. A medida que cambian y se modernizan las sociedades, las identidades étnicas se pueden ver reforzadas y la etnopolítica puede llegar a ser simplemente una forma de politización (Stavenhagen, 2000: 33-34).

Los procesos de configuración de los Estados-naciones modernos se basan en un concepto cívico de nación. La nacionalidad, en este caso, está determinada jurídicamente y asociada a una ciudadanía común. La arquitectura de la nación moderna exige, así, la subordinación de la nación basada en criterios étnicos. En este sentido es pertinente lo señalado por Oommen (Giménez, 2000) al sugerir la idea de etnicización para entender el proceso por el que ciertas colectividades son definidas y percibidas como foráneas (outsiders), es decir, como extranjeras en sus propios territorios. Dependiendo de las características específicas de los contextos sociohistóricos, habría diferentes tipos de etnicización. Siguiendo a este autor, el caso del norte chileno se trataría de la transformación de los habitantes originarios del territorio en una colectividad minoritaria y marginalizada durante la colonia y luego en tiempos republicanos; primero por el Estado nación peruanos y luego por el Estado nación chileno. Estos continúan habitando sus territorios ancestrales, pero prácticamente han sido desposeídos de los mismos mediante la alteración radical de sus vínculos tradicionales con los mismos. Esta situación ha llevado a que en la actualidad la residencia urbana o rural tenga escasa relevancia en la adscripción étnica. Es decir, vivir en localidades rurales tales como Isluga, Parka, Camiña, o urbanas, como Pozo Almonte, Alto Hospicio o Iquique (ver Figura $N^{\circ} 1$ ), no es tan importante como pertenecer a grupos de parentesco descendientes de los 
Figura $\mathrm{N}^{\circ} 1$

Actual Región de Tarapacá

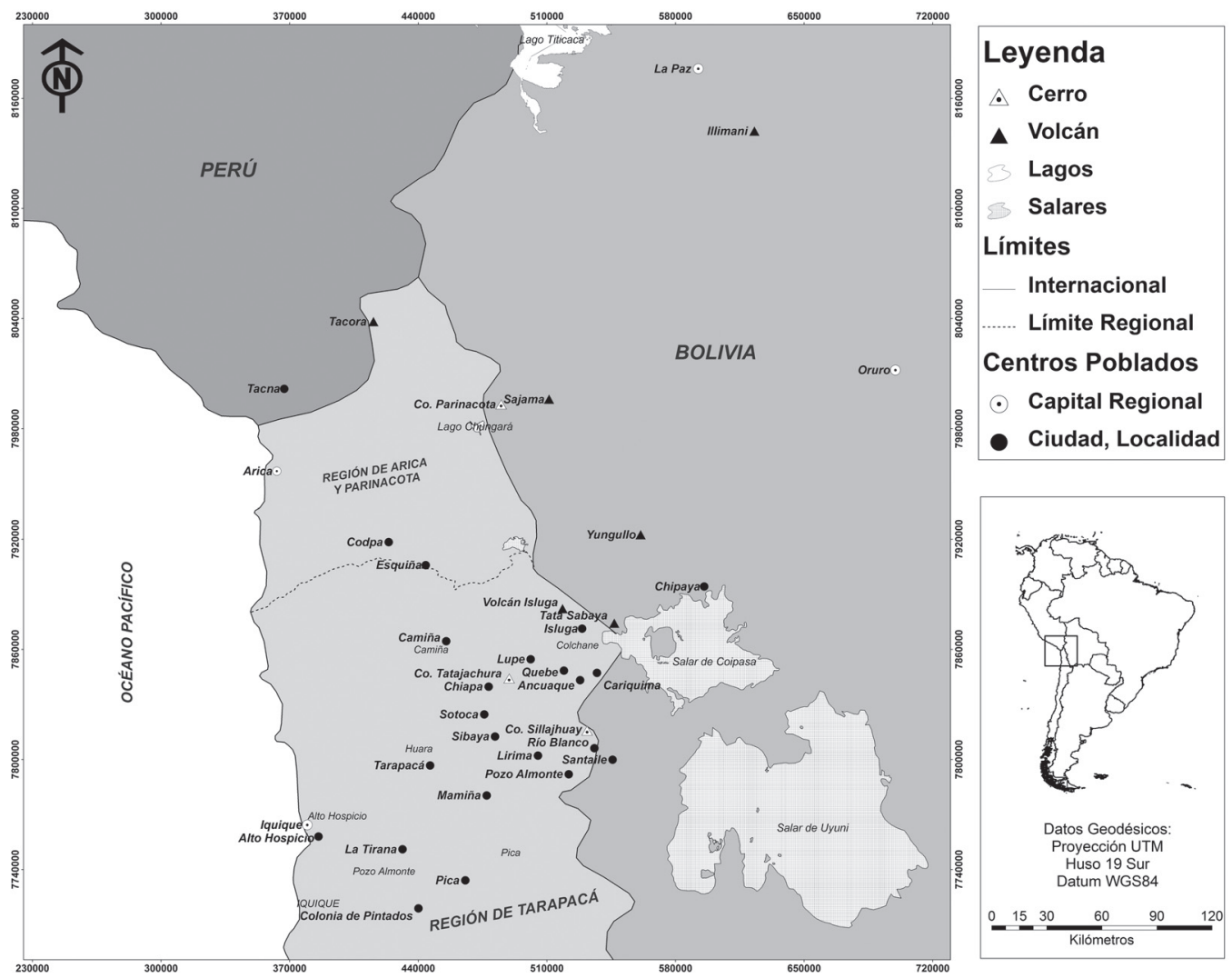

Fuente: Elaboración propia.

pueblos de indios configurados durante el período colonial. Los datos empíricos nos informan que la alteridad por parte de los pueblos indígenas respecto de la no indígena se sustenta en el pasado colonial y la república temprana. En tanto que las diferencias entre aymaras, quechuas y chipayas se basan en argumentos elaborados con base en variaciones de una misma matriz cultural (Cf. Gavilán et al., 2011).

De acuerdo con Oommen la nación y la etnia comparten el mismo contenido cultural, salvo la relación con el territorio. Ambas son comunidades culturales que comparten una denominación común, mitos de origen, una lengua propia o adoptada, una historia también común, una cultura distintiva y un sentido de lealtad y solidaridad. La diferen- cia específica radica en la relación con el territorio. Una nación sería una colectividad cultural plena y exitosamente identificada con un territorio. Es la fusión entre territorio y cultura, o también entre territorio y lenguaje, lo que constituye una nación. También el Estado comporta un territorio; pero hay una diferencia esencial. El territorio estatal es una entidad legal que determina el ámbito de jurisdicción del Estado. El territorio nacional, en cambio, es una entidad moral y cultural que resulta de la apropiación simbólico-expresiva del espacio; es un territorio-signo que funciona a la vez como envoltorio corporal y como emblema básico de la comunidad nacional. Para Oommen, el territorio cultural sería, juntamente con el lenguaje, la condición mínima para la existencia y la emergencia de la nación. Esto no equivale a negar la 
concepción de la nación como "comunidad imaginada" propuesta por Anderson. Se trata más bien de complementarla asignándole un soporte a la vez material y simbólico. Una nación no podría mantener su ethos cultural e incluso su identidad como comunidad imaginada sin la visibilidad que le confiere la referencia a un territorio que le sirva como lugar de anclaje, como espacio de inscripción y como referente simbólico (Giménez, 2000).

Contrariamente a la nación, una etnia sería una "nación desterritorializada", es decir, una comunidad cultural disociada real o simbólicamente de su territorio ancestral por desplazamiento forzado, por despojo o por la reformulación jurídica de su relación con la tierra en términos instrumentales (circunscripción político-administrativa, régimen de propiedad, etc.) y no ya en términos simbólico-expresivos. El territorio étnico reviste las mismas características simbólicas y culturales que el territorio nacional, pero lo que para el grupo nacional es objeto de identificación y de apropiación plena, para las etnias es permanente objeto de reclamo, de disputa $y$, en muchos otros casos, de nostalgia y recuerdo. Porque es la disociación -real o simbólicaentre territorio y cultura lo que define la etnicidad (Giménez, 2000).

Una particularidad que presenta la dinámica sociocultural en Tarapacá es que el proceso de marginación ha sido doble durante el período republicano, ya que la Guerra del Pacífico (1879) despojó al Estado y nación peruanos y al Estado y nación bolivianos del territorio que hoy se denomina como norte grande e instaló al Estado y nación chilenos en un momento en el que estos últimos ya estaban consolidados. El Estado chileno diseñó estrategias para ejercer soberanía y adscripción a la patria, período que los sociólogos e historiadores regionales han Ilamado proceso de chilenización ${ }^{5}$. Las comunidades de origen indígena inscribieron rápidamente sus propiedades en los nuevos registros estatales y fueron adoptando, paulatinamente, la nacionalidad chilena (González y Gundermann, 2009). Las localidades de Mamiña y

\footnotetext{
5 Ver Van Kessel, 1980; González, 1995; Castro, 2004, Figueroa y Silva, 2006.
}

Pica mantuvieron la nacionalidad peruana un tiempo más largo debido a los avances nacionalistas alcanzados por el Estado y nación peruanos en ellas ${ }^{6}$.

El Estado y la sociedad chilena han insistido en una sola identificación cultural legítima para sus ciudadanos de derecho pleno y han tendido a aplicar etiquetas reductivas a los pueblos indígenas en general y a la población procedente de los países vecinos que habitan en Tarapacá. Estas etiquetas incluyen las características fenotípicas de las personas tanto como las culturales (discriminación racial y cultural). Los datos acopiados indican que la adscripción nacional se ha logrado con éxito tanto en el caso chileno y boliviano. Sin embargo, se ha tratado de un proceso complejo y difícil. No ha sido fácil para las comunidades de origen indígena ser reconocidas como connacionales, debido justamente a la puesta en cuestión de sus lealtades culturales. $\mathrm{H}$. González (1997) plantea que posguerra del Pacífico la cultura pasa a ser el símbolo de la extranjeridad sometida y del atraso o barbarie. Desde ese momento cuando un aymara usa su ropa tradicional, desarrolla sus ritos o habla su lengua, no solo es indio-estigmatizado durante la colonia y luego como ciudadano del naciente Perú republicano, sino también el estereotipo de los países vecinos. Ataviado de su cultura, en la imagen de Titicaco del dibujante Pepo, señala la imagen que Chile tiene de Bolivia.

Giménez (2000) nos informa que en inglés existe el término "national" para designar a los individuos reconocidos como miembros de una nación en el sentido cultural del término, lo que no ocurre en español, agudizando la confusión con la ciudadanía. Los súbditos de un Estado que forman parte de la nación en el sentido cultural del término ("nationals"), son también invariablemente ciudadanos. En cambio, los que no se consideran parte de ella se les cuestiona su membresía; se puede ser ciudadano de un Estado, sin ser "national", es decir, sin ser reconocido como miembro de la comunidad nacional por el grupo cultural y políticamente dominante.

\footnotetext{
6 La mayoría de la población tarapaqueña se concentró en estas localidades hasta la década de los sesenta del siglo decimonónico.
} 
Hay que distinguir, entonces, entre ciudadanía, membresía nacional y membresía étnica. La confusión generada por el uso del término "ciudadano" para designar indistintamente tanto al súbdito de un Estado como al miembro de la nación tal como es definida por los grupos cultural y políticamente dominantes deriva de la identificación errónea entre nación y Estado planteada por Gellner (2001).

Gundermann (2003) afirma que en Tarapacá y Arica la formación de una conciencia nacional peruana fue un fenómeno anterior a la Guerra del Pacífico, pero la conciencia de pertenencia a una comunidad de iguales, a una nación estaba posiblemente restringida a círculos de los que no participaba la mayoría de la población de las localidades y comunidades indias. Sostiene que a fines del siglo XIX un grado de adhesión y entrega personal equivalente solo la tenía la identificación con la comunidad local no con una comunidad nacional.

"Una situación diferente experimentaron los pueblos en los que se concentraron las elites coloniales y de la temprana república, pues estos habrían efectuado un tránsito de nacionalidad, de identidad nacional, pero nunca pusieron en duda ni aceptaron retornar a la condición infamante de indio" (Gundermann (2003: 174).

Dado que a fines de los ochenta y principalmente durante la década de los noventa del siglo XX las comunidades de valles se reconocen como aymara, este autor señala que

"resulta paradójico que casi un siglo más tarde, bajo la neodenominación de aymara, la antigua etnia india diseñe elaboradas estrategias para ganar una nueva lucha por las clasificaciones y las nominaciones, ahora posicionados en el Estado una elite de la etnia aymara pugna por ganar el reconocimiento de aymara por quienes, bajo su formulación histórica de indio, desde el siglo XIX la habían repugnado" (Gundermann, 2003: 174).

La ciudadanía en sentido pleno tiende a concebirse en la reciente literatura sociológica como un instrumento para rectificar las desigualdades individuales y colectivas, muchas de las cuales proceden precisamente de las pertenencias étnicas. Es lo que ha estado sucediendo en nuestro continente. Como lo han señalado otros autores para América Latina, el auge de la etnicidad constituye una respuesta política de los descendientes de los pueblos originarios en el escenario nacional (Giménez, 2000; Guerrero y Ospina, 2003; Bello 2004; Gundermann, 2003). La demanda por mayor inclusión a la sociedad (Estado y nación) se entiende en un contexto histórico de exclusión. La información obtenida en esta investigación sustenta la hipótesis de que la comunidad de origen indígena en el norte chileno constituye una de las colectividades más marginadas del sistema político chileno.

Dadas las características particulares del proceso de integración al Estado nación chilenos, la membresía nacional no ha sido fácil. Durante el siglo XX estas colectividades han bregado por alcanzarla, lográndolo definitivamente con la ley indígena actual; no obstante, la participación política real es aún una cuestión pendiente. Giménez (2000), entre otros autores, ha sugerido que las demandas de las colectividades de origen indígena en América Latina por mayor inclusión a la sociedad se entiende en un contexto histórico de exclusión. Propone que para comprender su situación social y política en los Estados naciones modernos se precisa distinguir los distintos planos de la ciudadanía. Una cosa es formar parte de la comunidad nacional y otra ser miembros de una comunidad política y el carácter de la pertenencia a esta última considera diferentes tipos de derechos. En este sentido, la etnicidad y sus vínculos con la ciudadanía dependen de las particularidades de los Estados. Bengoa (2000 y 2009) ha argumentado que los procesos de emergencia indígena plantean el desafío de una nueva ciudadanía, pues ser ciudadano de la nación y miembro del pueblo indígena no implica contradicción. Sugiere que hemos asistido a un proceso de descolonización, en el que los indígenas buscan apropiarse como "ciudadanos étnicos" de los instrumentos e instituciones del Estado y no retraerse a sus comunidades originarias. Sin embargo, sostiene que si bien los avances hacia el reconocimiento de los pueblos originarios por parte de la sociedad nacional y del Estado son significativos, no podemos dejar de ver que la hegemonía cultural persiste en la práctica social y en la práctica jurídica. 


\section{Membresía étnica. Los argumentos para definir las pertenencias y las diferencias}

Las colectividades de origen indígena de la zona de estudio basan su etnicidad en las categorías coloniales indio/q'ara. Mientras la primera proviene del grupo dominante, la segunda deviene de la diferenciación que la población originaria, aymara hablante, asigna al "otro" (no indio). Como se señala más arriba, al interior de las colectividades que dicen descender de los pueblos originarios en la actual Región de Tarapacá se presentan tres distinciones importantes: el grupo aymara, el quechua y el chipaya. Este último, se ha diferenciado del aymara y del quechua desde tiempos coloniales. La colectividad quechua en Tarapacá es reciente y se ha configurado como resultado de fragmentaciones internas en el contexto de las dinámicas de las luchas por el reconocimiento por parte del Estado y nación chilenos.

Los procesos de transformaciones sociales y culturales ocurridos en esta región, no han borrado los límites étnicos. Si bien la subordinación de las tradiciones culturales de los pueblos originarios promueve procesos de homogeneidad cultural, la frontera étnica se mantiene tanto por la voluntad de los propios descendientes, como por efecto de los procesos de dominación social y cultural. El pasado de los aymaras y de los quechuas se sintetiza en el Inca, antepasado que se configura como representación del pasado, figura que los distingue de quienes no descienden del mismo. Se trata de un marcador de filiación compartida, a lo cual se agregan las lenguas originarias, los atributos fenotípicos, la religiosidad y la ocupación territorial. En este sentido, la pertenencia se vincula a la representación de una historia común, que se revitaliza a través de mitos y acciones rituales. En tanto que la identidad étnica es producida en los procesos de interacción social, mismas que, a diferencia de gran parte del siglo XX, hoy se enmarca principalmente en las ciudades nortinas.

La lucha que han desplegado las colectividades por el reconocimiento de las diferencias culturales y étnicas y el propio accionar del Estado, en el contexto de un modelo neoliberal, ha generado el relevamiento de la identidad étnica y el eclipsamiento de otras identidades como las de clase y género. Las políticas de discriminación positiva han generado un proceso de concienciación étnica que va promoviendo una nueva forma de pertenencia nacional y a la comunidad política.

Con algunas variaciones, en los tres grupos la religiosidad constituye un referente importante de identidad étnica. Los aymaras, colectividad mayoritaria y con una historia reivindicativa más antigua en la región, enfatizan en las diferencias con los no indígenas. Los quechuas expresan una voluntad clara por distinguirse tanto de los aymaras como de la población que no se adscribe étnicamente. Los chipayas tienden a subordinar su pertenencia étnica a la nacional como una estrategia para acceder a la residencia y a beneficios sociales; pero también debido a sus históricos conflictos con la población aymara. Se sienten diferentes tanto a estos últimos (chilenos y bolivianos) como a los jalisco

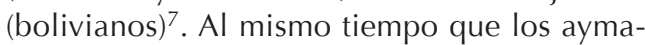
ras los perciben como otro grupo, asociados al pasado (orígenes del pueblo indio) lo que designan como "chullpa", término que hoy contiene cierta connotación negativa de "lo atrasado" o incivilizado.

Las tres colectividades estudiadas argumentan que las prácticas religiosas, especialmente el carácter de los rituales, son diferentes. Sin embargo, el análisis de las mismas muestra los mismos componentes culturales. Entre los quechuas, se insiste en la ceremonia de las cuatro esquinas para brindar a las deidades, en contraposición a la que realizarían los aymaras, quienes lo harían en el centro. Se trataría de una antigua práctica realizada, también, por la población que se adscribe hoy al pueblo aymara. El culto a Pachamama, emblema de la alteridad con los no indígenas, es similar en los tres casos. Ocurre lo mismo con los santos patronos y

\footnotetext{
7 Los jalisco son un grupo quechua proveniente de la zona de Potosí que ha comenzado a explorar esta zona como destino para la obtención de un empleo. Al parecer se trataría de un grupo reducido de personas. Recogimos aquí el argumento entregado por jornaleros chipayas que, al momento de la investigación, se encontraban trabajando en la comuna de Camiña.
} 
antepasados. Una de las festividades comunes que se conmemora en toda la región son los carnavales. Las variaciones que adquieren las diferentes modalidades de celebración tienen que ver con el grado de secularización alcanzado por sus adherentes. En la Región de Tarapacá se observan dos extremos. En el lugar de mayor apego a lo religioso (al ciclo anual de fiestas y calendario ritual) se hallan las comunidades altiplánicas, en tanto que en la ciudad de Iquique, junto con restringirse a dos antiguos barrios, el carácter sagrado se pierde por su desvinculación de las divinidades originarias. Estas variaciones son percibidas por los entrevistados como aspectos que justifican diferencias étnicas y culturales. La comunidad quechua de Mamiña, por ejemplo, selecciona como elemento marcador de alteridad la inclusión de los bailes tradicionales como el cachimbo y la cueca, ambas son danzas representativas de las repúblicas peruana y chilena. Por otra parte, la organización de la celebración gira en torno a dos grupos: "Los Progreso" y "Los verdes", en los que se agrupa a las unidades domésticas consideradas "mamiñanas", identificadas por sus apellidos ${ }^{8}$ y distribuidas territorialmente en el pueblo. El primero integrado por "los pobres" y el segundo "económicamente más acomodados", nos recuerda la organización de la misma fiesta en el altiplano en torno a la mitad de arriba (arajj saya=mayor prestigio) y la de abajo (manqha saya=menor prestigio).

Los aymaras desarrollan argumentos para distinguirse especialmente de "los occidentales", es decir de lo que para ellos es la cultura occidental, manifiesta en la sociedad no indígena como un bloque. Se busca afirmar diferencias a través del resaltamiento de virtudes de "la cultura indígena" por oposición a "la cultura occidental", tendiendo a cosificarlas. Los dirigentes aymaras y quechuas conciben a sus pueblos como naciones, en tanto que en la población no dirigente aún se percibe una fuerte identidad localista. El uso de la lengua es, para los dirigentes, la base de la identidad, aunque la gran mayoría no la

\footnotetext{
8 Aunque en estos pueblos residen familias provenientes de la zona altiplánica o de otras ciudades del país desde hace mucho tiempo, estas son consideradas como forasteras a pesar de sus niveles de integración a la vida económica y social.
}

maneja. Entre los chipaya, la identidad local se expresa en una marcada endogamia, a pesar de su tendencia al cambio. Situación que también se presentaba en las comunidades de Isluga y Cariquima en la década de los setenta y ochenta (Gavilán, 1996). No obstante, la regla endogámica es más flexible para las mujeres que para los varones; práctica vinculada al sistema de propiedad de la tierra asignada a los hombres. Entre los quechuas existe una fuerte intención por diferenciarse de los aymaras debido a los conflictos que surgieron durante el proceso de reconocimiento estatal. La principal diferencia se asienta en la convicción de que tanto las costumbres, los apellidos y las actividades económicas se distinguen según los pisos ecológicos (valles y altiplano).

En general, son las diferenciaciones socioeconómicas y sociopolíticas construidas durante el período colonial y temprana república las que llevan a los dirigentes a sostener diferencias étnicas en la actualidad. La pertenencia-no pertenencia se determina por los apellidos lo que implica identificar a las familias "fundacionales". Entre los quechuas la memoria colectiva recuerda su pasado peruano en un contexto de persecución y represión ejercida por el Estado y sociedad chilenos. Esto justifica su identificación con la comunidad quechua de Perú.

En los tres casos la música constituye otro referente identitario. Las habilidades manifiestas para ejecutar instrumentos contribuyeron a la inserción laboral y social de los hombres en las oficinas salitreras. La experiencia de vida en estos campamentos es relatada por las personas con un fuerte componente discriminatorio por parte de la población no indígena. Se sintieron diferentes y menoscabados: "decían mira ese indio viene de Mamiña". Esta situación fue especialmente vivida en la escuela. Algunos padres prohibieron a sus hijos cultivar la música o hacer de esta actividad un oficio como un mecanismo para desprenderse del estigma de indio y posibilitar la movilidad social.

La identificación quechua en la localidad de Mamiña se inicia a partir de la agencia de profesionales con experiencia municipal en localidades rurales y como una estrategia organizativa para acceder a los recursos del 
Estado. Son los conflictos con los líderes aymaras que dirigieron el accionar de la institucionalidad estatal. Uno de sus principales dirigentes argumenta que se trató de crear la organización como una más, entre otras, dirigidas a obtener beneficios sociales y/o a proteger sus recursos productivos. Esta búsqueda de mayor integración y o mayor participación social en la sociedad nacional también se registró durante la década de los sesenta cuando crearon la juntas de vecinos. Pero el reconocimiento de esta nueva adscripción por parte del Estado (CONADI) no fue fácil, pues los dirigentes regionales aymaras se opusieron. Después de una larga lucha y de negociaciones con las autoridades nacionales logran ser reconocidos como quechuas.

En la actualidad, los chipayas son contratados como músicos en las fiestas que realizan los aymaras chilenos. Se piensan a sí mismos mejores en el manejo de los instrumentos de viento. Si bien esta colectividad es considerada por sus vecinos aymaras como gente del pasado, están lejos de ser tales. Como inmigrantes buscan empleos en las ciudades o en los valles interandinos. Cuando logran legalizar su documentación y la residencia intentan acceder a beneficios sociales reflexionando sobre los escenarios socioeconómicos y políticos en Bolivia y en Chile. En conjunto, presentan menores niveles de escolaridad que los quechuas y aymaras y por lo menos durante el siglo XX y en la actualidad suelen emplearse en familias campesinas que hoy se adscriben étnicamente en Chile. La particularidad de esta primera década del siglo XXI es que se van radicando de manera definitiva en las ciudades del norte; desarrollando actividades como comercio menor, obreros en los municipios rurales, medieros agrícolas, y o como peones de quintas o chacras. Todo ello, sin perder sus vínculos con su comunidad de origen.

En todos los casos la base de la diferencia cultural está dada por la identidad asignada y por la autoelaborada. En este proceso de identificación se recupera la visión del no indígena: piel morena, bajos de estatura, apeIlidos autóctonos, vestimenta, gastronomía, entre otros. Si a ello agregamos los fuertes sentimientos de pertenencia a sus localidades de origen (un grupo de parentesco, un santo patrono) en las que disponen de pequeñas propiedades agrícolas familiares y o derechos sucesoriales a los pastales, observamos que la diferencia cultural se elabora a partir del orden colonial. La categoría estamental de 'indio', del periodo colonial y su posterior proyección en las repúblicas criollas, ha servido de base para la adscripción étnica actual (Gundermann, 2003). Este autor postula que la condición de indio o indígena sería el antecedente histórico más importante para comprender la identidad colectiva de hoy. La identidad local estaría asociada a las comunidades históricas, pero existiría una más amplia que correspondería a un estrato, una categoría social particular sujeta a relaciones de dominación; la cual no sería una identidad étnica, porque resulta de una fusión de un conjunto de realidades socioculturales discretas, distinguibles y que se reconocían como específicas, como diferentes en tiempos precolombinos. Pero también sería premoderna, tampoco es algo equivalente a una nación. Esta afirmación se inscribe en un concepto de etnia diferente a la que aquí postulamos, pero coincidimos en que las pertenencias étnicas hoy elaboradas en el contexto de la sociedad nacional y el Estado moderno se relacionan con la historia común vivida bajo el estatus de "indio". Pero la voluntad que expresan para lograr mayor inclusión social utilizando esta condición nos estaría hablando de un proceso reflexivo por parte de actores sociales concretos que observan su condición subalterna y definen estrategias para cambiar de posición (Figura $N^{\circ} 2$ ).

\section{Membresía nacional. Modernización desde arriba y nacionalismo desde abajo}

Los datos acopiados indican que la población de origen indígena experimenta la nacionalidad como cualquier otro connacional tarapaqueño. Los dirigentes que reivindican derechos culturales conciben a los pueblos originarios como naciones al interior del Estado, sin embargo manifiestan claras lealtades a las naciones hegemónicas. La escuela pública y el servicio militar han sido los espacios en los cuales se ha aprendido a ser moderno y se han elaborado los sentimientos nacionalistas. Los entrevistados han adoptado los preceptos patrióticos basados en el éxito de la Guerra del Pacífico. Los himnos forman parte de 
Figura $\mathrm{N}^{\circ} 2$

Distribución de la población por adscripción étnica

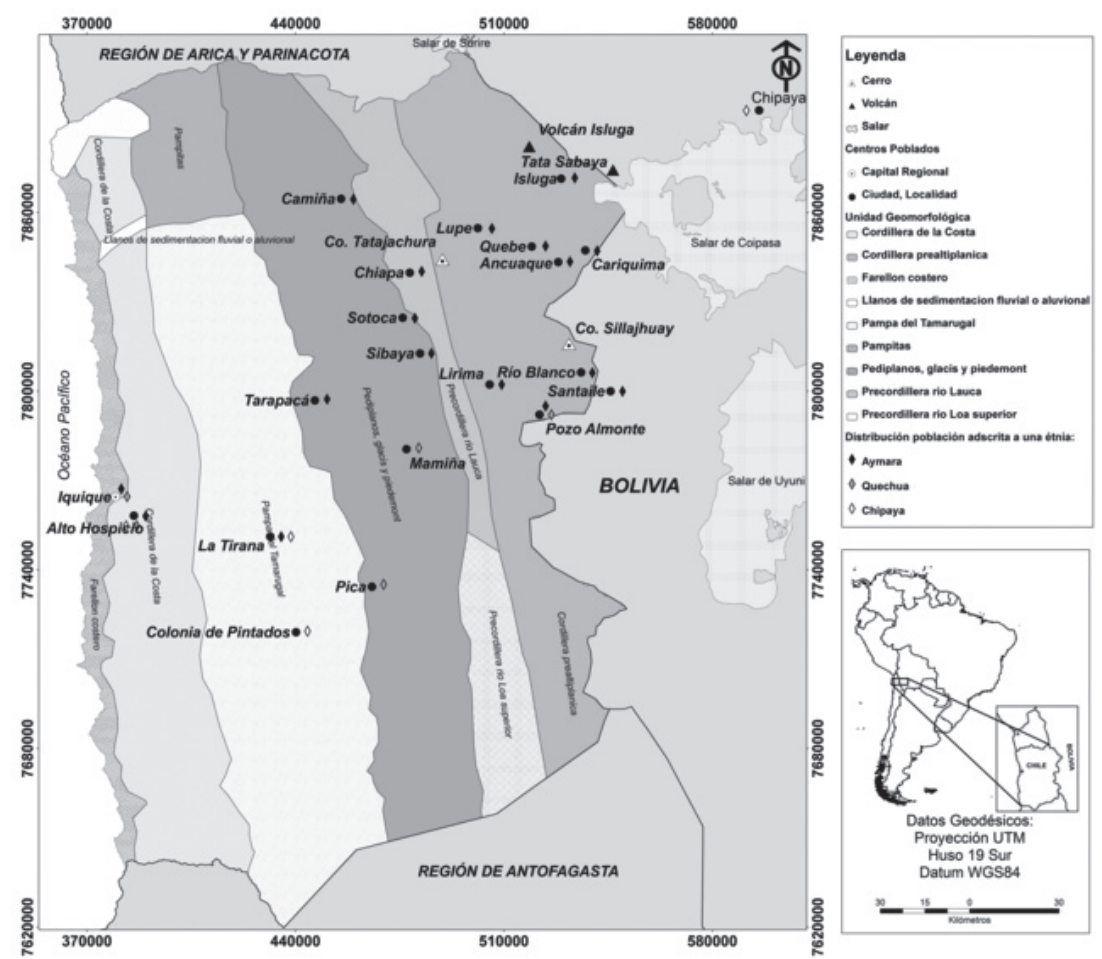

Fuente: Elaboración propia.

su historia personal, se identifican con la bandera, dicen ser chilenos por oposición a bolivianos y peruanos a quienes tratan como extranjeros.

Es entre los quechuas que aparece la asociación directa entre etnia y nacionalidad: "Los abuelos dijeron que eran quechuas y peruanos". Se percibe un pasado propio, diferente a otras localidades. Antes del reconocimiento indígena en la localidad de Mamiña, se identificaban solamente con la nación, como un recurso para despojarse del estigma de ser indío ("Antes éramos chilenos no más"). Piensan hoy que fue una equivocación haber eclipsado su pasado indígena, aunque entienden que este ocultamiento ocurrió por la discriminación que experimentaron en la escuela.

En la memoria colectiva del pueblo de Mamiña el pasado peruano está más presen- te que en otras colectividades. La adopción de la nacionalidad chilena no fue inmediata y se elaboró en medio de los conflictos que generó el nuevo orden republicano en la región: "mi abuela tenía una caja, donde eso era sagrado, ahí nosotros teníamos carné peruanos".

Los chipayas se sienten extranjeros en Chile y así los consideran los aymaras y quechuas chilenos. Expresan lealtad a los símbolos nacionales de Bolivia. Hay en la memoria la idea de que sus antepasados siempre vinieron a la costa. Dicen buscar la nacionalidad chilena en el contexto de las condiciones de inserción laboral y el mercado de la vivienda. Se observa la preeminencia de la adscripción étnica frente a los aymaras bolivianos y chilenos. Los conflictos territoriales con sus vecinos en Bolivia han sido documentados por historiadores y antropólogos (Ver Wachtel, 2001). Ellos argumentan que "los aymaras 
han castigado mucho a los chipayas... a nuestros abuelos, tatarabuelos les han pegado mucho...". La fuerte emigración de la población joven hacia Chile ha generado conflictos internos. Quienes han permanecido en su localidad perciben cambios importantes en las formas de vida de los emigrantes, mismos que tienen que ver con la adquisición de nuevas herramientas para enfrentar la vida actual y sobre todo para enfrentar la dominación aymara. Son discriminados doblemente, por su condición étnica y nacional y distinguen el trato recibido como trabajadores. Sostienen que los "patrones" no indígenas los tratan mejor que los "patrones" aymaras.

La extranjería nacional es bastante explícita entre aymaras y chipayas, pero también con la población peruana a la hora por competir por un puesto de trabajo o por beneficios sociales.

Los chipayas tienden a agruparse en la región en torno a clubes deportivos para mujeres y para hombres lo que ha permitido mantener a la colectividad unida. Las competencias con otros clubes locales les han servido para interactuar con otras colectividades y con los municipios, así buscan ser reconocidos como inmigrantes. De aquí que tiendan a superponer la dimensión nacional de su identidad, pues así pueden acceder a la residencia, optar por mejores empleos y terminar con la relación de subordinación respecto de los aymaras.

\section{La conciencia ciudadana. Derechos sociales y políticos}

Los aymaras fueron los que lideraron el proceso de inclusión en el proyecto país que se inaugura con la transición a la democracia. Se trató de la primera organización supralocal que reivindica derechos culturales en la provincia de Iquique. Los primeros dirigentes reflexionan sobre su lucha y son críticos con los grupos de poder que lideran el sistema político y que manifiestan clara resistencia a poner en cuestión a la nación chilena. Sus aspiraciones apuntan a insertarse en una sociedad moderna en la que se pueda enfrentar las relaciones de poder entre culturas diferentes. Este cuestionamiento, sin embargo, va de la mano de un concepto y un hacer política restringidos. Uno de los pro- blemas más serios que enfrentan es la imposibilidad de crear una organización amplia y representativa. Existe un gran distanciamiento entre dirigentes y bases, los conflictos que ha generado la inserción de los líderes en puestos públicos los lleva a una dispersión que ha estancado un proceso contestario. Si bien reconocen un retroceso, lo explican por la intromisión de los partidos políticos lo que habría implicado la pérdida de credibilidad y confianza en los líderes. Aunque la desconfianza y baja participación política es generalizada en la región, los dirigentes de la causa indígena enfrentan mayores dificultades para lograr acuerdos, convocar a las comunidades y por la escasa experiencia de ejercicio político en el escenario histórico nacional. Los dirigentes incursionan principalmente en un contexto en el que los partidos políticos no son representativos de la mayoría de los y las ciudadanas, se fueron alejando de los proyectos ideológicos que caracterizó la lucha social durante el siglo XX y en el que la pragmática orienta las prácticas. Esto ha jugado en contra de un desarrollo que les permita elaborar análisis críticos de las actuales condiciones de dominación. Algunos dirigentes expresan su sorpresa y no pueden explicar el comportamiento electoral de la gran mayoría de la población que se adscribe étnicamente en la región. Uno de los aspectos que destacan es la desviación que se produce entre las manifestaciones de apoyo a determinados candidatos y luego optan por otro. En realidad, la gran mayoría vive al margen de las dinámicas políticas actuales, tendiendo a mantener lealtades locales en las elecciones municipales, en tanto que en las parlamentarias y presidenciales optan por factores personales. Tienden a ejercer un tipo de ciudadanía corporativa. La relación entre dirigentes y bases; así como entre autoridades y ciudadanos se puede calificar de paternalista y clientelista. A pesar de que la conciencia cívica en el país ha experimentado un revés, en el caso de los pueblos originarios de Tarapacá se presentan particularidades puesto que son los últimos en llegar a la modernización política; y por otra parte, las alternativas para enfrentar el orden político actual se mantiene igual que al término de la dictadura militar. La lucha por el reconocimiento indígena es la plataforma que les facilita un nuevo estatus de ciudadanía. Se va expandiendo la conciencia 
étnica y estableciendo un vínculo diferente con el Estado y sociedad nacional.

Entre los dirigentes se observan distintas visiones del problema y serias dificultades para llegar a consensos. Una de ellas cuestiona el poder de las iglesias y del Estado a través de la escuela y de las políticas dirigidas a los pueblos originarios. Otra justifica la adaptación al orden actual. Y una tercera postula que se debe trabajar hacia adentro ofreciendo servicios a las comunidades en la ciudad. Aquel sector crítico a la institucionalidad estatal argumenta que las organizaciones deben independizarse; sin embargo, este discurso está lejos de articular un movimiento que reivindique mayor participación política. La afirmación de la diferencia cultural aún se basa en la falsa dicotomía: sociedad indígena/sociedad occidental, simplificando así una realidad mucho más compleja. Se abstrae la posición estructural que ocupan y han ocupado en la historia regional. No realizan un cuestionamiento a las políticas públicas vinculadas a sus vidas y sin embargo se refieren a las "políticas occidentales" elaboradas por "los blancos" quitándoles a estos conceptos sus contenidos históricos. Se persigue denunciar y contrarestar la discriminación cultural, racial y étnica pero no las desigualdades sociales en las que estas se inscriben.

En el caso de los chipayas, un dirigente plantea la posibilidad de luchar por el reconocimiento como agrupación étnica en Chile, apelando a su historia. Nos planteó la siguiente cuestión: “¿Qué nos conviene más, ser chipaya o bolivianos no más?" Creen que reivindicar sus derechos étnicos en territorio chileno podría llevarlos a perder la nacionalidad boliviana y con ello el acceso a beneficios sociales que reciben en su país. Interpretan básicamente la situación política actual en ambos países y reflexionan sobre las estrategias a seguir para mejorar su posición social: "Un presidente indígena puede mejorar la situación de los indígenas, pero ser chilenos puede ayudar a conseguir un terreno para vivir".

La población chipaya en Chile vive procesos similares a cualquier inmigrante actual. La emigración ocurre por mejores condiciones laborales y de vida en general. Los efectos de la indocumentación (cárcel, deportación y explotación laboral) son evi- tados mediante un cambio de apellidos para pasar por aymaras chilenos, permaneciendo en las localidades rurales con menor control policial y acercándose a las ciudades hasta solicitar la residencia.

Las elites aymara y quechua luchan por integrarse a la sociedad chilena como grupos culturalmente diferenciados, al mismo tiempo que el Estado continúa desplegando diversas estrategias para lograr la homogenización cultural. Sus prácticas emancipatorias se dirigen a ser reconocidos como pueblos indígenas, pero estas se limitan a alcanzar derechos sociales y derechos a la diferencia cultural, a veces únicamente a través del folclore ${ }^{9}$. Aquella cultura cívica proveniente de la tradición europea no está presente y en general se observa un tipo de ciudadanía subordinada al Estado y al mercado. Sin embargo, la conciencia de pertenencia a un grupo culturalmente subordinado y la búsqueda por ocupar una posición diferente en la comunidad política continúa y se abre paso lentamente.

Todo lo anterior es producto de la particular forma que tienen las colectividades descendientes de los pueblos de indios de estar en la modernidad. Siguiendo a Jorge Larraín, las particularidades que presenta el proceso de inclusión/exclusión de la población indígena determinan un tipo de modernidad precaria y periférica (Larraín, 1994: 16). En esta línea, la multidimensionalidad que conlleva el análisis del proceso modernizador, nos Ileva a plantear que los grupos étnicos del norte grande atraviesan un proyecto emancipador, renovador y democratizador más lento que el que ha sostenido el pueblo mapuche en el sur del país. Aquella cultura cívica de la república ha sido adoptada, con las particularidades locales, por la población no indígena. Los procesos de secularización en la región de Tarapacá han ocurrido de manera diferenciada. La racionalización de la vida social y el individualismo creciente van afectando a

\footnotetext{
9 Esta tendencia se observa en las ferias andinas patrocinadas por el Estado. Una imagen patética, pero muy gráfica se observó en la inauguración de la multitienda Almacenes Paris en Iquique cuando un antiguo dirigente aymara, ahora funcionario público, realiza una "pawa" como signo de la identidad regional.
} 
los grupos que van vinculándose con las dinámicas que promovió el capitalismo rentista y la expansión del movimiento obrero. Los procesos de integración al mercado de trabajo impulsados por el desarrollo de la industria del salitre desde fines del siglo XIX y primera mitad del XX impactaron de manera diferenciada a las diferentes colectividades existentes en este desértico territorio. La zona más cercana a los centros urbanos, esto es, los valles interandinos, se articulan antes que las comunidades ubicadas en la zona altiplánica a través de la venta de mano de obra o vía venta de productos agropecuarios. Quienes se integraron de manera estructural a estas dinámicas fueron alejándose de las comunidades (lo que se podría llamar fuga étnica) y otra parte recupera sus lazos motivados por acceder a beneficios sociales y/o a reflexionar críticamente sobre las relaciones de poder impuestas por el Estado y la sociedad dominante. La escolaridad masiva constituyó un aspecto clave para lograr los objetivos de modernización deseados por parte del Estado y por las comunidades de origen indígenas como un medio para la movilidad social y alejar su pasado indígena.

\section{Palabras finales}

Como ha sucedido en general en América Latina, la modernidad en Tarapacá es un proceso inacabado, polarizado y desigual. La población que hoy se adscribe a los pueblos aymara, quechua y chipaya es heterogénea social, económica, cultural y políticamente. Ello es válido tanto en su interior como entre los grupos. Como hemos visto, el pueblo chipaya presenta los menores niveles de modernización, a pesar de su evidente integración a los mercados de trabajo, al sistema educacional y/o a las dinámicas sociales urbanas; es también el más vulnerable por su posición de inmigrantes extranjeros, de nacionalidad boliviana. El pueblo quechua, emerge por la voluntad de algunos dirigentes por distinguirse de los aymaras a partir de la disputa por poder y por acceder a los beneficios estatales. Si bien el grupo de personas que se adscribe a los pueblos quechua y aymara chilenos se integraron tempranamente al mercado de trabajo regional, la secularización va procediendo a un ritmo más lento que la población no indígena debido a que la escolaridad masiva va ocurriendo a partir de los años sesenta. Los datos acopiados muestran que el nivel de escolaridad adquiere un peso relevante en el distanciamiento de la religiosidad como referente explicativo de la vida social y moral, en un cambio significativo en la concepción del tiempo/espacio y, en consecuencia, en las formas de reflexionar críticamente de manera independiente de la comunidad local y de la hegemonía del Estado y del mercado.

Distinguir la membresía étnica, la membresia nacional y ciudadanía nos permite una aproximación más cercana a la realidad regional. Si bien la condición de ser indio en la actualidad va dejando atrás su pasado colonial para transformarse en un puente hacia la inclusión social a la sociedad nacional y a la comunidad política, el desarrollo de una conciencia crítica es incipiente, aunque en expansión. Los datos muestran que si bien la agencia social está presente en la vida cotidiana que procura bienestar, la transición de indio a ciudadano diferenciado culturalmente aún está en construcción. Para un segmento importante de la población de origen indígena el apego a la tradición es una estrategia racional. El discurso de la tradición es un pretexto para generar mayores y mejores procesos de inclusión al Estado-nación. Para un grupo minoritario, esto es, para aquellos con más edad, menos escolaridad y hablantes de las lenguas originarias, la tradición provee herramientas para el presente y futuro en el espacio local.

Los datos obtenidos permiten postular que en la actualidad en el norte del país la etnicidad es más una respuesta a la oferta del Estado que una demanda al mismo. No obstante, es claro también, que la fuerza de la identidad étnica está en la lucha -ya iniciada- como reacción a la histórica clasificación del estigma de ser indio.

\section{Referencias bibliográficas}

ACOSTA, O. Los Urus, cazadores de parinas. Eco Andino, 1997, Vol. 3, p. 7-29.

APPADURAI, A. La Modernidad Desbordada. Buenos Aires: Ediciones Trilce y Fondo de Cultura Económica, 2001. 
BARTOLOMÉ, M.A. Gente de costumbre y gente de razón. Las identidades étnicas en México. México: Instituto Nacional Indigenista y Siglo XXI Editores, 1997.

BENHABIB, S. Las reivindicaciones de la cultura. Igualdad y diversidad en la Era Global. Buenos Aires: Katz Editores, 2006.

BELLO, A. Etnicidad y ciudadanía en América Latina. Santiago de Chile: Series Libros de la CEPAL N 69, 2004.

BENGOA, J. La emergencia indígena en América Latina. Santiago de Chile: Fondo de Cultura Económica, 2000.

BENGOA, J. ¿Una segunda etapa de la emergencia indígena en américa latina? Cuadernos de Antropología Social, 2009, Vol. 29, p. 7-22.

CASTRO, L. Una escuela fiscal ausente, una chilenización inexistente: la precaria escolaridad de los aymara durante el período de expansión del salitre (1880-1920). Cuadernos Interculturales, 2004, №3, p. 57-68.

CUCHE, D. La noción de Cultura. Buenos Aires: Nueva Visión, 2000.

DÍAZ-COUDIER, E. Diversidad cultural y educación en Iberoamérica. Revista Iberoamericana de Educación, 1998, № 17, p. 11-30.

FIGUEROA, C. y SILVA, B. Entre el caos y el olvido: la acción docente en la provincia de Tarapacá-Chile (1880-1930). Cuadernos Interculturales, 2006, $\mathrm{N}^{\circ}$ 6, p. 37-53

GAVILÁN, V. Mujeres y Hombres en Isluga y Cariquima: una aproximación a las relaciones entre los aymara del norte de Chile. Quito: Tesis para optar al grado de maestría en Antropología, FLACSO, 1996.

GAVILÁN, V.; VIGUERAS, P.; PARRA, M.; MADARIAGA, C.; MORALES, N. Y ANDRADE, R. La sociedad y la cultura andina contemporánea: estudio de los saberes para la salud y la enfermedad en los pueblos originarios del norte de Chile. Revista Andina, 2011, $N^{\circ} 252$, p. 571-600.
GELLNER, E. Naciones y nacionalismo. Madrid: Alianza Editorial, 2001.

GIMÉNEZ, G. Comunidades Primordiales y modernización en México. En: GIMÉNEZ, G. y POZAS, R. (coordinadores). Modernización e identidades. México: Instituto de Investigaciones Sociales, UNAM, 1994, p. 151-183.

GIMÉNEZ, G. Etnia, estado de la cuestión. En: REYNA, L. (coordinadora). Los retos de la Etnicidad en los Estados-nación del siglo XXI. México: CIESAS, 2000, p. 45-70

GUERRERO, F. y OSPINA, P. El poder de la comunidad. Ajuste estructural y movimiento indígena en Los Andes Ecuatorianos. Buenos Aires: CLACSO, 2003.

GONZÁLEZ, H. Apuntes sobre el tema de la identidad cultural en la región de Tarapacá. Estudios Atacameños, 1997, p. 13-20

GONZÁLEZ, H. y GUNDERMANN, H. Sociedades indígenas y conocimiento antropológico: aymaras y atacameños de los siglos XIX y XX. Chungará, 2009, Vol. 41, N 1, p. 113-164.

GONZÁLEZ, S. El poder del símbolo en la chilenización de Tarapacá: Violencia y nacionalismo entre 1907 y 1950. Revista de Ciencias Sociales, 1995, № 5, p.29-40.

GUNDERMANN, H. Ciudadanía y poblaciones indígenas andinas de Chile. En: GUNDERMANN, H; FOERSTER GONZÁLEZ, R. y VERGARA ESTÉVEZ, J.A. Mapuches y Aymaras el debate en torno al reconocimiento y los derechos ciudadanos. Santiago de Chile: RIL editores, Predes, 2003.

LARRAÍN, J. Trayectoria a la modernidad. Santiago de Chile: Centro de Estudios Públicos, 1994, p. 313-333.

MUÑOZ, C. Procesos identitarios en los inmigrantes de origen chipaya en la región de Tarapacá. Santiago de Chile: Tesis para optar al grado de licenciado en Antropología Social, Universidad Academia de Humanismo Cristiano, 2010. 
PAUWELS, G. Los Últimos Chullpas, Alfred Metraux en Chipaya (Enero-Febrero de 1931). Eco Andino, 1998, Año 3, Vol. 6, p. 41-82.

POUTIGNAT, Ph. y STREUFF-FENART, J. El Ámbito de Investigación de la Etnicidad: Cuestiones Claves. Théories de l'ethnicité. París: Presses Universitaires de Francem, 1995, p. 154-188.
STAVEnhaGeN, R. Conflictos Étnicos y Estado Nacional. México: Siglo XXI, 2000

VAN KESSEL, J. Holocausto al progreso. Los aymaras de Tarapacá. Amsterdam: CEDLA, 1980.

WACHTEL, N. El Regreso de los antepasados. Los indios Urus de Bolivia, del siglo XX al XVI. México: Fondo de Cultura Económica, 2001. 
